\title{
A Dipicolinic Acid Tag for Rigid Lanthanide Tagging of Proteins and Paramagnetic NMR Spectroscopy
}

\author{
Xun-Cheng Su, ${ }^{\dagger}$ Bradley Man, ${ }^{\ddagger}$ Sophie Beeren, ${ }^{\ddagger}$ Haobo Liang, ${ }^{\dagger}$ Shane Simonsen, ${ }^{\dagger}$ \\ Christophe Schmitz, ${ }^{\S}$ Thomas Huber ${ }^{\S}$ Barbara A. Messerle, ${ }^{\ddagger}$ and Gottfried Otting ${ }^{\star, \dagger}$ \\ Research School of Chemistry, Australian National University, Canberra ACT 0200, Australia, School of Chemistry, \\ University of New South Wales, Sydney NSW 2052, Australia, and School of Molecular and Microbial Sciences and \\ Australian Institute for Bioengineering and Nanotechnology, University of Queensland, \\ Brisbane QLD 4072, Australia
}

Received May 19, 2008; E-mail: gottfried.otting@anu.edu.au

Site-specific labeling of a protein with a lanthanide ion $\left(\mathrm{Ln}^{3+}\right)$ provides access to a wealth of paramagnetic effects that contain long-range structural information and can be measured by nuclear magnetic resonance (NMR) spectroscopy. ${ }^{1}$ In particular, pseudocontact shifts (PCS) induced by lanthanides can be used to determine the structure of protein-protein and protein-ligand complexes rapidly from a minimum amount of NMR data ${ }^{2}$ and the paramagnetically induced weak alignment of the protein in the magnetic field leads to residual dipolar couplings (RDCs) which contain detailed information about the structure and dynamics of proteins. ${ }^{3}$ Correspondingly, many efforts have been directed toward the development of tags for site-specific attachment of lanthanides to proteins, including fusions with lanthanide-binding peptides ${ }^{4}$ and chemical derivatization of cysteine residues with synthetic peptides and lanthanide-chelating reagents. ${ }^{5-10}$

Several features must be considered in the design of suitable lanthanide tags. (i) Rigidity of the attachment, as PCS and RDCs are greatly reduced when the lanthanide tag reorientates with respect to the protein. ${ }^{6,10}$ In addition, variation in the metal ion position prevents interpretation of the PCS by a single magnetic susceptibility anisotropy $(\Delta \chi)$ tensor. (ii) Enantiomeric purity, as metal ions can act as chiral centers and different enantiomers of the metalchelate would lead to diastereomeric protein-tag constructs, therefore doubling the number of NMR peaks. ${ }^{5,7,11}$ (iii) Proximity of the metal ion to the protein, as accurate determination of the $\Delta \chi$ tensor requires adequate sampling of the space around the metal ion. ${ }^{10}$ (iv) Ease of use. For example, lanthanide tags that are anchored to the protein via two disulfide bonds immobilize the tag well with respect to the protein. This requires, however, two cysteine residues with thiol groups positioned at the correct distance to react with a single tag molecule. ${ }^{8}$ Here we describe a simple lanthanide tag and strategy for immobilization of a lanthanide close to the protein using a single cysteine residue.

4-Mercaptomethyl-dipicolinic acid (4MMDPA, 1) coordinates metal ions in a nonchiral fashion and can be readily attached to a cysteine thiol group via a disulfide bridge using established dithionitrobenzoate chemistry. ${ }^{9}$ Lanthanides bind dipicolinic acid (DPA) with nanomolar affinity for the first DPA ligand and decreasing affinities for additional DPA ligands up to the $\left[\operatorname{Ln}(\mathrm{DPA})_{3}\right]^{3-}$ complex. ${ }^{12}$ A protein derivatized with one molecule of $\mathbf{1}$ thus leaves the free coordination sites on any metal ion bound to $\mathbf{1}$ available for binding to additional ligands. In the case of lanthanides, carboxyl groups of the protein are particularly suitable ligands that can act as additional anchors for tethering the lanthanide ion to the protein. Simultaneous coordination of the

\footnotetext{
† Australian National University.

* University of New South Wales.

§ University of Queensland.
}

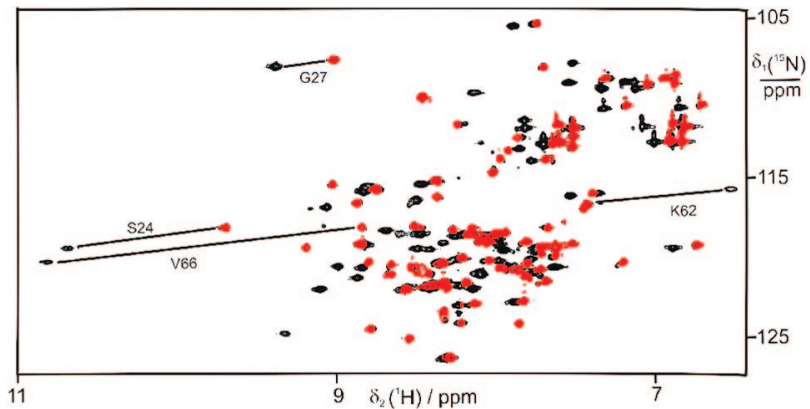

Figure 1. Superimposition of ${ }^{15} \mathrm{~N}$ HSQC spectra of uniformly ${ }^{15} \mathrm{~N}$-labeled ArgN derivatized with 1 at Cys68 in the presence of a 1:1 mixture of $\mathrm{Lu}^{3+}$ and $\mathrm{Yb}^{3+}$ (black) and in the presence of $\mathrm{Lu}^{3+}$ (red). The ratio of lanthanides to protein was about $1.5: 1$. The spectra were recorded at $25^{\circ} \mathrm{C}$ and $\mathrm{pH} 6.5$ at a ${ }^{1} \mathrm{H}$ NMR frequency of $800 \mathrm{MHz}$.

lanthanide ion by $\mathbf{1}$ and one or several protein carboxyl groups provides an avenue for creating high-affinity lanthanide binding sites that immobilize the lanthanide ion with respect to the protein.<smiles>O=C(O)c1cc(CS)cc(C(=O)O)n1</smiles>

For experimental verification, we derivatized the N-terminal DNA-binding domain of the Escherichia coli Arginine repressor (ArgN) with 1 to form ArgN-4MMDPA and recorded ${ }^{15} \mathrm{~N}$ HSQC spectra in the presence of different lanthanide ions (Figure 1). For each backbone amide, a single cross-peak was observed in the presence of $\mathrm{Lu}^{3+}$ or any other lanthanide. $\mathrm{Yb}^{3+}$ induced PCS of up to $2 \mathrm{ppm}$.

Lanthanide binding was highly specific, that is, an up to 4-fold excess of lanthanides did not change the protein NMR spectrum. The lanthanide binding affinity of ArgN-4MMDPA was on par with that of DPA, as titration of the ArgN-4MMDPA construct with a 1:1 complex of $\mathrm{Lu}^{3+}$ and DPA resulted in cross-peaks of metal-free and $\mathrm{Lu}^{3+}$-bound ArgN-4MMDPA of similar intensity (Supporting Information). In contrast, titration of ArgN-4MMDPA with [Yb(DPA $\left.)_{2}\right]^{-}$ did not yield paramagnetically shifted cross-peaks, showing that ArgN4MMDPA cannot extract $\mathrm{Yb}^{3+}$ from the $\left[\mathrm{Yb}(\mathrm{DPA})_{2}\right]^{-}$complex. The ArgN-4MMDPA- $\mathrm{Ln}^{3+}$ complex seems incapable of binding an additional DPA molecule with significant affinity, as ${ }^{15} \mathrm{~N}$ HSQC spectra of ArgN-4MMDPA prepared with a 1:1 mixture of $\mathrm{Lu}^{3+}$ and $\mathrm{Yb}^{3+}$ yielded the same PCS as corresponding spectra with a 1:1 mixture of $[\mathrm{Lu}(\mathrm{DPA})]^{+}$and $[\mathrm{Yb}(\mathrm{DPA})]^{+}$(Supporting Information). 


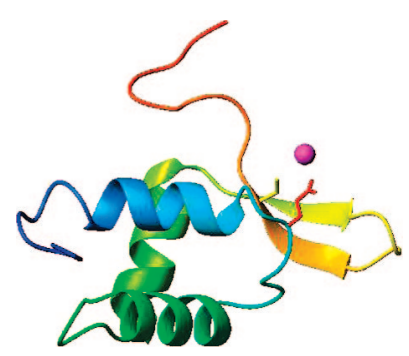

Figure 2. Ribbon representation of the DNA-binding domain of the $E$. coli arginine repressor: ${ }^{13}$ blue, $\mathrm{N}$-terminus; red, C-terminus; magenta, position of the lanthanide ion in the ArgN-DPA construct. The Cys68 (yellow) and Glu21 (red) side chains are shown as sticks.

For maximal accuracy, PCS and RDCs were measured in samples containing 1:1 mixtures of diamagnetic $\left(\mathrm{Lu}^{3+}\right)$ and paramagnetic $\left(\mathrm{Tb}^{3+}, \mathrm{Tm}^{3+}\right.$, or $\left.\mathrm{Yb}^{3+}\right)$ lanthanides. The possibility of measuring RDCs from aligned (paramagnetic) and unaligned (diamagnetic) protein molecules present in the same sample is a unique advantage over RDC measurements using alignment media. An EXSY spectrum of a mixture of $[\mathrm{Lu}(\mathrm{DPA})]^{+}$and $[\mathrm{Yb}(\mathrm{DPA})]^{+}$complexes showed that the metals exchange with a rate constant of about 0.1 $\mathrm{s}^{-1}$ at $25^{\circ} \mathrm{C}$, that is, the simultaneous presence of two different metal ions does not result in noticeable exchange broadening.

The PCS measured for the ArgN-4MMDPA complexes with $\mathrm{Tb}^{3+}, \mathrm{Tm}^{3+}$, and $\mathrm{Yb}^{3+}$ were used to determine the $\Delta \chi$ tensor parameters of the respective lanthanides. The program Numbat ${ }^{14}$ afforded a simultaneous fit of all three tensors to a common lanthanide position with respect to the protein. Performing the fit for all $23 \mathrm{NMR}$ conformers of ArgN, the metal position varied by less than $\pm 1.2 \AA$, being on average within $4.6 \AA$ of the sulfur atom of Cys68 and within $2.6 \AA$ of one of the carboxyl oxygens of Glu21. The $\mathrm{Ln}^{3+}$-oxygen distance agrees with $\mathrm{Ln}^{3+}$-oxygen distances in the literature, ${ }^{15}$ indicating that Glu21 coordinates the lanthanide ions. The carboxyl group of Glu21 is the only carboxyl group in the vicinity of Cys68.

To assess the rigidity of lanthanide binding, we compared the $\Delta \chi$ tensors determined from PCS with the alignment tensors determined from the RDCs of the backbone amides of the regular secondary structure elements of the ArgN-4MMDPA complexes with $\mathrm{Tb}^{3+}, \mathrm{Tm}^{3+}$, and $\mathrm{Yb}^{3+}$. In the case of a molecule aligned with the magnetic field by virtue of its paramagnetism, the alignment tensor should be directly proportional to the $\Delta \chi$ tensor (see also footnotes of Table S3):

$$
A_{\mathrm{ax}, \mathrm{rh}}=\frac{B_{0}^{2}}{15 \mu_{0} k T} \Delta \chi_{\mathrm{ax}, \mathrm{rh}}
$$

where $B_{0}$ is the magnetic field strength, $\mu_{0}$ is the induction constant, $k$ is the Boltzmann constant, and $T$ is the temperature. Flexibly attached lanthanide ions result in smaller $\Delta \chi$ and alignment tensors as well as in discrepancies between the orientations of the tensor axes. ${ }^{10}$ In the case of the three paramagnetic ArgN-4MMDPA$\mathrm{Ln}^{3+}$ complexes, the orientations of the principal axes of alignment and $\Delta \chi$ tensors were in close agreement as expected for rigid lanthanide coordination. In addition, the axial components of the tensors closely obeyed equation 1 , while the large uncertainties in the determination of the rhombic components prohibited comparison (Supporting Information).

The magnitudes of the $\Delta \chi$ tensors observed for the ArgN4MMDPA- $\mathrm{Ln}^{3+}$ complexes are only about half as big as those reported for proteins and peptides ${ }^{10,16}$ which may be a consequence of lanthanide coordination with rapidly exchanging water molecules. Nonetheless, the 4MMDPA tag offers many attractive advantages, including its small size and thus reduced likelihood of interference in studies of intermolecular interactions, its formation of stable nonchiral 1:1 complexes with metal ions, the capability of immobilizing lanthanides near the protein surface, and its straightforward chemical synthesis (Supporting Information).

Acknowledgment. Supported by the Australian Research Council.

Supporting Information Available: Protocols for the synthesis of 4MMDPA and ligation to proteins; ${ }^{15} \mathrm{~N}-\mathrm{HSQC}$ spectra of $\mathrm{ArgN}$ 4MMDPA with $\mathrm{Lu}^{3+}, \mathrm{Tb}^{3+}$, and $\mathrm{Tm}^{3+}$; plot of amide chemical shift differences $\mathrm{ArgN} / \mathrm{ArgN}-4 \mathrm{MMDPA}-\mathrm{Lu}^{3+}$ versus amino acid sequence; amide chemical shifts of ArgN-4MMDPA with $\mathrm{Lu}^{3+}, \mathrm{Tb}^{3+}, \mathrm{Tm}^{3+}$, and $\mathrm{Yb}^{3+}$; RDC data; Sanson-Flamsteed plots of the $\Delta \chi$ and alignment tensors; correlation plots of experimental and calculated PCS and RDCs. This material is available free of charge via the Internet at http:// pubs.acs.org.

\section{References}

(1) Pintacuda, G.; John, M.; Su, X.-C.; Otting, G. Acc. Chem. Res. 2007, 40, 206-212.

(2) (a) Pintacuda, G.; Park, A. Y.; Keniry, M. A.; Dixon, N. E.; Otting, G. J. Am. Chem. Soc. 2006, 128, 3696-3702. (b) John, M.; Pintacuda, G.; Park, A. Y.; Dixon, N. E.; Otting, G. J. Am. Chem. Soc. 2006, 128, 49975009 .

(3) (a) Bax, A.; Grishaev, A. Curr. Opin. Struct. Biol. 2005, 15, 563-570. (b) Tolman, J. R.; Ruan, K. Chem. Rev. 2006, 106, 1720-1736. (c) Lakomek, N. A.; Carlomagno, T.; Becker, S.; Griesinger, G. J. Biomol. NMR 2006, 34, 101-115. (d) Bouvignies, G.; Markwick, P. R. L.; Blackledge, M. Chemphyschem 2007, 8, 1901-1909.

(4) (a) Ma, C.; Opella, S. J. J. Magn. Reson. 2000, 146, 381-384. (b) Wöhnert, J.; Franz, K. J.; Nitz, M.; Imperiali, B.; Schwalbe, H. J. Am. Chem. Soc. 2003, 125, 13338-13339. (c) Martin, L. J.; Hähnke, M. J.; Nitz, M.; Wöhnert, J.; Silvaggi, N. R.; Allen, K. N.; Schwalbe, H.; Imperiali, B. J. Am. Chem. Soc. 2007, 129, 7106-7113.

(5) Ikegami, T.; Verdier, L.; Sakhaii, P.; Grimme, S.; Pescatore, B.; Saxena, K.; Fiebig, K. M.; Griesinger, C. J. Biomol. NMR 2004, 29, 339-349.

(6) Rodriguez-Castañeda, F.; Haberz, P.; Leonov, A.; Griesinger, C. Magn. Reson. Chem. 2006, 44, S10-S16.

(7) Prudêncio, M.; Rohovec, J.; Peters, J. A.; Tocheva, E.; Boulanger, M. J.; Murphy, M. E. P.; Hupkes, H. J.; Kosters, W.; Impagliazzo, A.; Ubbink, M. Chem.-Eur. J. 2004, 10, 3252-3260.

(8) (a) Keizers, P. H. J.; Desreux, J. F.; Overhand, M.; Ubbink, M. J. Am. Chem. Soc. 2007, 129, 9292-9293. (b) Vlasie, M. D.; Comuzzi, C.; van den Nieuwendijk, A. M. C. H.; Prudêncio, M.; Overhand, M.; Ubbink, M. Chem.-Eur. J. 2007, 13, 1715-1723.

(9) Su, X.-C.; Huber, T.; Dixon, N. E.; Otting, G. Chembiochem 2006, 7, 1599 1604.

(10) Su, X.-C.; McAndrew, K.; Huber, T.; Otting, G. J. Am. Chem. Soc. 2008, $130,1681-1687$.

(11) Pintacuda, G.; Moshref, A.; Leonchiks, A.; Sharipo, A.; Otting, G. J. Biomol. NMR 2004, 29, 351-361.

(12) Grenthe, I. J. Am. Chem. Soc. 1960, 83, 360-364.

(13) Sunnerhagen, M.; Nilges, M.; Otting, G.; Carey, J. Nat. Struct. Biol. 1997, 4, 819-826.

(14) Schmitz, C.; Stanton-Cook, M. J.; Su, X.-C.; Otting, G.; Huber, T. J. Biomol. NMR 2008, 41, 179-189.

(15) Parker, D.; Dickins, R. S.; Puschmann, H.; Crossland, C.; Howard, J. A. K. Chem. Rev. 2002, 102, 1977-2010.

(16) Bertini, I.; Janik, M. B. L.; Lee, Y.-M.; Luchinat, C.; Rosato, A. J. Am. Chem. Soc. 2001, 123, 4181-4188.

JA803741F 